\title{
A CGCM Study on the Northward Propagation of Tropical Intraseasonal Oscillation over the Asian Summer Monsoon Regions
}

\author{
Shu-Ping Weng ${ }^{1, *}$ and Jin-Yi Yu ${ }^{2}$ \\ ${ }^{1}$ Department of Geography, National Taiwan Normal University, Taipei, Taiwan, ROC \\ ${ }^{2}$ Department of Earth System Science, University of California, Irvine, USA
}

Received 11 November 2008, accepted 18 February 2009

\begin{abstract}
This study performs numerical experiments to (1) examine the influences of Pacific and Indian Ocean couplings on the propagation of tropical intraseasonal oscillation (ISO) in the extended boreal summer (May-through-October) and (2) determine the relative contributions of the ocean coupling and internal atmospheric dynamics to the ISO propagation over the Asian-Pacific monsoon regions. For (1), three basin-coupling experiments are performed with a coupled atmosphere-ocean general circulation model (CGCM), in which the air-sea coupling is limited respectively to the Indian Ocean, the Pacific Ocean, and both the Indian and Pacific oceans. For (2), three forced experiments are performed with the atmospheric GCM (AGCM) component of the CGCM, in which the sea surface temperature (SST) climatologies are prescribed from the CGCM experiments. Using extended Empirical Orthogonal Function and composite analyses, the leading ISO modes are identified and compared between the observation and the model experiments. The CGCM modeling results show that the Indian ocean coupling is more important than the Pacific Ocean coupling to promoting both zonal and meridional propagations of the summertime ISO. In this season, the Indo-Pacific warm pool retracts westward and shifts into the Northern Hemisphere allowing the Indian Ocean coupling to become more important. The Indian Ocean coupling is found to promote the northward propagation mainly through wind-evaporation feedback, whereas in observations the cloud-radiation feedback is found to be equally important. The AGCM modeling results indicate that monsoonal dynamics aid the meridional ISO propagation mainly in the low-level winds. Without the ocean coupling, the northward ISO convection feature is weaker and is limited by the northern boundary of climatic easterly vertical shear. The ocean coupling enables the simulated ISO-related convections to cross the northern boundary of the shear. This modeling study concludes that the Indian Ocean coupling plays a crucial rather than a secondary role for the observed northward propagation of summertime ISO.
\end{abstract}

Key words: Intraseasonal oscillation, Atmosphere-ocean coupling, Madden-Julian oscillation, Indo-Pacific climate variability, Easterly vertical shear

Citation: Weng, S. P. and J. Y. Yu, 2010: A CGCM study on the northward propagation of tropical intraseasonal oscillation over the Asian summer monsoon regions. Terr. Atmos. Ocean. Sci., 21, 299-312, doi: 10.3319/TAO.2009.02.18.01(A)

\section{INTRODUCTION}

Tropical intraseasonal oscillation (ISO; Madden and Julian 1994; Zhang 2005) is characterized by planetaryscale propagation in the moist convection and circulation anomalies. This quasi-periodic oscillation occupies a broad 20 - 90-day timescale and has been recognized as a phenomenon important to both weather forecast and climate prediction. Through the interactions with surface winds and sea surface temperatures (SSTs), for example, the ISO can

\footnotetext{
* Corresponding author

E-mail: znspw302@ntnu.edu.tw
}

affect tropical cyclone genesis in the Indian and western Pacific oceans (Liebmann et al. 1994), Australian region (Hall et al. 2001), Gulf of Mexico (Maloney and Hartmann 2000a), eastern North Pacific (Maloney and Hartmann 2000b), and western North Pacific (Kim et al. 2008). As another example, the onsets of summer monsoon in India, South China Sea-East Asia, and Indonesia-North Australia are often signified by the arrival of ISO's wet phase (e.g., Murakami et al. 1986; Chen and Chen 1995; Hung and Yanai 2004). The wet and dry spells of monsoon life cycle over the vast Asian-Australian monsoon regions are strongly 
regulated by the passage of ISO (e.g., Chen et al. 1988). The ISO is also considered a major source of stochastic forcing (Penland 1996; Hendon et al. 1999) important for the onset and demise of El Nino Southern Oscillation (ENSO) (McPhaden 1999). Due to its profound socioeconomic benefits once a successful ISO prediction can be made, this phenomenon has therefore intrigued numerous researchers during the past decades to study its origin, dynamical characteristics, and various mechanisms contributing to its propagation (see Wang 2005 for a comprehensive review).

Propagation characteristics of the ISO were noticed to change with the seasonal cycle in the Indo-Pacific sector. In boreal winter, ISO propagation is predominantly eastward. After being initiated in the western Indian Ocean, the ISO passes through the Maritime Continent, redevelops over the western Pacific warm pool, and often intersects the South Pacific convergent zone where the warm SSTs reside (Wang and Rui 1990; Jones et al. 2004). In boreal summer, the eastward ISO propagation weakens substantially as it approaches the Maritime Continent (e.g., Kemball-Cook and Wang 2001). A northward (or northwestward) propagation branch becomes prominent in the Asian-Pacific monsoon regions (Yasunari 1980; Lau and Chan 1986; Wang and Rui 1990; Hsu and Weng 2001; Hsu et al. 2004; Li and Wang 2005). Several mechanisms have been proposed to explain the northward propagation of summertime ISO. Webster (1983) suggested that destabilization of the boundary layer heat fluxes over the northern land surface can cause a northward shift of the equatorial convection. Hsu et al. (2004) also emphasized the air-land interaction for the northward propagation. They suggested that deep moisture convergence in the free atmosphere and boundary layer aided by the sloping terrain and stronger frictional effects over the landmass of South Asia can contribute to the northward propagation of ISO. Goswami and Shukla (1984) proposed a convectionthermal relaxation feedback mechanism to explain the oscillation. The occurrence of convection stabilizes the atmosphere which in-turn suppresses the convection itself, whereas simultaneous dynamical and radiation relaxation will setup the atmosphere to be convectively unstable again. Inferred from their numerical simulations, Lau and Peng (1990) suggested that while the equatorial moist Kelvin waves weaken after interacting with mean monsoonal circulations, unstable baroclinic waves can be produced over the Indian peninsula. Results of this interaction hence signify the northward advance of the ISO. Wang and Xie (1997) proposed that the northward ISO convection in the Indian Ocean (and western Pacific) is a manifestation of the northwestward emanation of Rossby waves from the equatorial Kelvin-Rossby wave packet when the latter travels through the Maritime Continent and rapidly decays in the central Pacific. Jiang et al. (2004) further showed that such a northward component of the Rossby waves can be attributed to several factors includ- ing the summertime off-equatorial mean easterly vertical shear (EVS) which characterizes the monsoon circulations, moisture advection in the boundary layer, and air-sea couplings. More recently, Wang (2005) suggested that the northward propagation of ISO in the Indian Ocean may be an unstable mode of atmospheric internal dynamics associated with the asymmetric monsoonal flow in boreal summer. These studies suggest that the existence of an off-equator EVS basic state provides an intrinsic mechanism for the ISO to propagate northward.

It has been noticed that there are coherent fluctuations between ISO-related convection and SST anomalies, which has prompted the suggestion that the atmosphere-ocean coupling may be an essential element of the tropical ISO dynamics. Field experiments indicated that ISO-induced SST anomalies can be as large as $2^{\circ} \mathrm{C}$ in the northern Indian Ocean and Bay of Bengal (Bhat et al. 2001; Webster et al. 2002). Similar connection between the ISO propagation and warm SST is also noted in the eastern North Pacific during the boreal summer (Maloney and Kiehl 2002). The influence of SST on the ISO is also evident during ENSO events. Observational (e.g., Woolnough et al. 2000) and modeling (e.g., Watterson and Syktus 2007) studies showed that the eastward extention of the western Pacific warm pool during El Nino events is accompanied by more eastward invasions of ISO-related SST, low-level zonal wind, and convection anomalies.

This study aims at comparing the relative importance between the ocean coupling and the internal atmospheric dynamics (such as those associated with the monsoon flow) to the meridional propagation of summertime ISO. In particular, we examine the importance of air-sea coupling in the Pacific and Indian oceans separately. These two ocean basins have different mean SST distributions and opposite mean surface wind directions associated with the Pacific and Indian cells of the Walker circulation. It is expected that air-sea interactions over two oceans may have different influences on the summertime ISO. A series of basin-coupling CGCM experiments is performed in this study and their ISO simulations are compared to examine this hypothesis. The basin-coupling modeling strategy of Yu et al. (2002) enables us to turn on the atmosphere-ocean coupling in the model over a specific ocean basin while the coupling is turned off everywhere else.

This paper is organized as follows. The basin-coupling methodology and the CGCM used in this study are described in section 2. The simulated summertime ISOs are contrasted with the observation in sections 3 . The role of the ocean coupling is discussed in section 4 . Section 5 summarizes the major findings of this study.

\section{MODEL AND BASIN-COUPLING EXPERIMENTS}

The CGCM (detailed in Yu and Mechoso 2001) used in 
this study consists of the UCLA AGCM (Mechoso et al. 2000) and GFDL Modular Ocean Model (MOM; Bryan 1969; Cox 1984). The AGCM has a global coverage with a horizontal resolution of $4^{\circ}$ in latitude and $5^{\circ}$ in longitude and 15 levels in the vertical with the top at $1-\mathrm{mb}$. The OGCM has a longitudinal resolution of $1^{\circ}$ and a latitudinal resolution varying gradually from $1 / 3^{\circ}$ between $10^{\circ} \mathrm{S}$ and $10^{\circ} \mathrm{N}$ to about $3^{\circ}$ at both $30^{\circ} \mathrm{S}$ and $50^{\circ} \mathrm{N}$. It has 27 layers in the vertical with $10-\mathrm{m}$ resolution in the upper 100 meters. The AGCM and OGCM are coupled daily without flux correction. Three basin-coupling experiments are performed: the Pacific Ocean (PO) Run, the Indian Ocean (IO) Run, and the Indo-Pacific (IP) Run. In the PO Run, CGCM includes only the Pacific Ocean $\left(30^{\circ} \mathrm{S}-50^{\circ} \mathrm{N}, 130^{\circ} \mathrm{E}-70^{\circ} \mathrm{W}\right)$ in its ocean model domain. The IO Run includes only the Indian Ocean $\left(30^{\circ} \mathrm{S}-50^{\circ} \mathrm{N}, 30-130^{\circ} \mathrm{E}\right)$ whereas the IP Run includes both the Indian and Pacific oceans $\left(30^{\circ} \mathrm{S}-50^{\circ} \mathrm{N}, 30^{\circ} \mathrm{E}-70^{\circ} \mathrm{W}\right)$ in the ocean model domain. Outside the ocean model domains, climatological monthly SSTs are prescribed. Inside the ocean model domains, SSTs polarward of $20^{\circ} \mathrm{S}$ and $30^{\circ} \mathrm{N}$ are relaxed toward their climatological values. Therefore, the effective coupling regions in these CGCM runs are limited to the tropical Pacific and Indian Oceans. All three runs were each integrated for 60 years. Only the last 30-yr integrations are analyzed in this study. The observed ISO properties in circulation and convection fields are derived respectively from the daily-mean European Re-Analysis product (ERA40; Uppala et al. 2005) and the pentad-mean CPC merged analysis of precipitation (CMAP; Xie and Arkin 1997) in their overlapped period of $1979-2001$.

The simulated SSTs from the IP Run are compared with the observation in Fig. 1 for the extended summer season (May-through-October; MJJASO). The observed climatology (1981 - 2001) (Fig. 1a) is calculated from NOAA Optimum Interpolation SST (OISST_v2; Reynolds et al. 2002). In the observation, the equatorial warm SSTs retreat to the west of the dateline from its wintertime counterpart (not shown). The distribution of the Indo-Pacific warm waters also become more asymmetric with respect to the equator, with the waters shift northward to cover the entire northern Indian Ocean and western Pacific (south of $20^{\circ} \mathrm{N}$ ). The general patterns of the observed Indo-Pacific SST distribution are reasonably captured in the simulation. The northward extension of warm SSTs in the Indian Ocean is realistically simulated. A similar northward extension is also produced in the western North Pacific, even though it does not extend as far north as in the observation. Although the gross features are quite realistic, the model SSTs tend to be colder than observed in the Indian Ocean. Other model deficiencies include a warm bias in the eastern Pacific, a too zonal and too eastward extension of the southern branch of the western Pacific warm pool, and a cold bias around the Maritime Continent (Fig. 1c). The two warm biases are associated with the so-called double ITCZ problem that many contemporary
CGCMs face (Mechoso et al. 1995). The SST climatologies produced by the IO and PO Runs (not shown) are generally similar to that of the IP Run.

\section{SUMMERTIME ISO IN THE BASIN-COUPLING CGCM EXPERIMENTS}

To extract the ISO signals, we adopt the procedure used by Rui and Wang (1990). The mean annual cycle is first removed from the daily data to produce daily anomalies. A 3-month running mean anomaly, which estimates the subannual-to-interannual variation, is then removed from the daily anomaly before computing the 5-day mean pentad anomaly. This band-pass filtering procedure retains intraseasonal variations with timescales ranging from 10 days to

(a) Observation

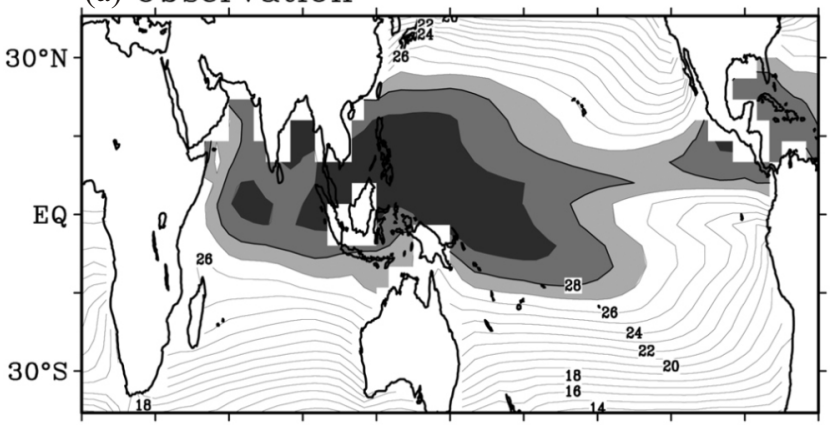

(b) IP Run

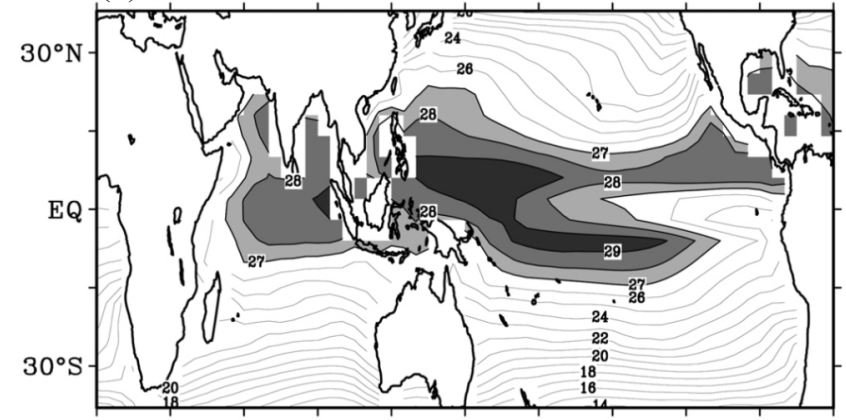

(c) IP Run - Observation

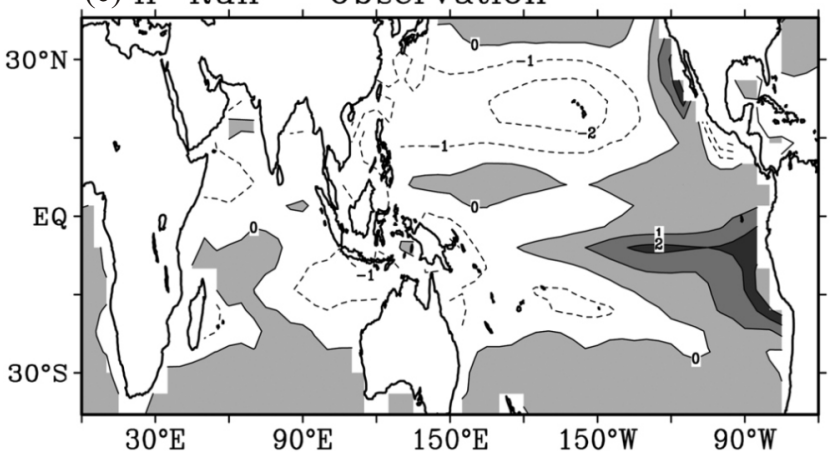

Fig. 1. The SST climatology calculated from: (a) NOAA OISST_v2 dataset (1981 - 2001); and (b) the Indo-Pacific (IP) CGCM Run during the boreal summer (May - Ocrober; MJJASO). The difference between them $\left[(b)\right.$ minus (a)] is also shown in (c). Contour intervals are $1{ }^{\circ} \mathrm{C}$. 
3 months. The CMAP precipitation dataset is also processed in a similar way but taking its pentad-resolution into account. We examined the variance of the simulated and observed filtered anomalies in $850-\mathrm{mb}$ zonal wind $\left(\mathrm{U}_{850}{ }_{850}\right)$ averaged between $10^{\circ} \mathrm{S}$ and $10^{\circ} \mathrm{N}$ during the MJJASO season (not show), and found that the maximum variance produced by the three CGCM experiments (which is located in the eastern Indian Ocean) is about $50 \%$ of the observed peak value. To identify the dominant ISO mode and its propagation characteristics, an Extended Empirical Orthogonal Function (EEOF) analysis (Weare and Nasstrom 1982) is applied to the filtered easterly vertical shear (EVS) anomalies in the tropical eastern hemisphere $\left(20^{\circ} \mathrm{S}-20^{\circ} \mathrm{N}, 30-\right.$ $180^{\circ} \mathrm{E}$ ) where the intraseasonal variance is concentrated. A 5-pentad lead-lagged window is used in the EEOF analysis. Here the EVS is defined as the difference between the anomalous zonal winds at 200 and at $850-\mathrm{mb}$ (i.e., $\mathrm{U}_{200}^{\prime}-\mathrm{U}^{\prime}{ }_{850}$ ). This quantity gives a good measurement of the strength of the gravest baroclinic mode associated with the large-scale deep convections (Wang and Fan 1999). We found applying the EEOF analysis to the EVS anomalies particularly effective in isolating the ISO from the model experiments where the intraseasonal variability is weak. Choice of this quantity is also in accord with the recent suggestion of Wheeler and Hendon (2004) that ISO is best identified when an EOF analysis is applied to the combined $\mathrm{U}_{200}^{\prime}, \mathrm{U}_{850}$, and the outgoing longwave radiation anomalies together.

The percentages of the 10-to-90 days EVS variance explained by the first EEOF modes for ERA-40 and the IP, PO, and $\mathrm{IO}$ runs are, respectively, $11.0 \%, 8.4 \%, 8.2 \%$, and $10.3 \%$. For the sake of discussion, only the half cycle of the first EEOF modes from the observed and simulated EVS evolutions in three CGCM experiments is shown in Figs. 2a - d. In Fig. 2, a convergent (divergent) zone in the $850-\mathrm{mb}$ level is denoted at the zero contour line of EVS with positive (negative) anomalies to its right and negative (positive) anomalies to its left. The observation (Fig. 2a) shows that the leading ISO mode is characterized by a wavenumber- 1 pattern with its convergence/divergence center propagating eastward along the equator. This is similar to the leading EEOF modes obtained when the analysis was applied to the boreal winter ISO (see Fig. 3 of Weng and Yu 2010). Unlike its wintertime counterpart, a northwest-to-southeast tilting in the zero contour line of EVS anomaly signifies a northward propagation branch. The zero line in the eastern Indian Ocean moves from the equator in phase 1 to about $20^{\circ} \mathrm{N}$ in phase 4 . The observed eastward and northward propagations over the Indian Ocean sector are reasonably simulated by both IP (Fig. 2b) and IO (Fig. 2d) runs. Lacking of the Indian Ocean coupling, the PO Run (Fig. 2c) shows a larger standing component.

The composited ISO lifecycle in various variables is then portrayed by subtracting the mean of 20 most extreme negative events from that of 20 most extreme positive events.
These ISO events (each with a 50-day time window) were selected based on the ordered values of the principal component time series in the first EEOF mode of EVS. The same procedure is applied to all the CGCM experiments to construct the simulated ISO lifecycles.

Figure 3 shows the Hovmoller diagrams of the composite ISO lifecycle in $200-\mathrm{mb}$ velocity potential anomalies $\left(\chi^{\prime}{ }_{200}\right)$ along the tropical band $\left(2^{\circ} \mathrm{S}-14^{\circ} \mathrm{N}\right)$. It should be noted that the contour interval used for the CGCM results (Figs. $3 b-d$ ) is only $1 / 3$ of that used for the observation (Fig. 3a), because the simulated ISO intensity is weaker than the observed one. In the observation (Fig. 3a), three active centers with enhanced anomalous amplitude can be identified when the $\chi_{200}^{\prime}$ pattern propagates eastward: near the Arabian Sea-western coasts of the Indian subcontinent $\left(60-75^{\circ} \mathrm{E}\right)$, the Maritime Continent-western Pacific (120 $\left.150^{\circ} \mathrm{E}\right)$, and the eastern tropical Pacific-Central America $\left(120-90^{\circ} \mathrm{W}\right)$. When approaching these regions, the ISO propagating speed also slows down. The center in the Indian Ocean is well captured in the IP Run (Fig. 3b) and is best reproduced in the IO Run (Fig. 3d), but is very weak in the PO Run (Fig. 3c). The IO Run reproduces the eastward propagation of this center most realistically. These results suggest that the Indian Ocean coupling strengthens the ISO intensity and its eastward propagation in the Indian Ocean sector. The Maritime Continent-western Pacific center is simulated by all the three model runs. The PO Run has the strongest intensity and the IP Run captures the eastward propagation more realistically. The PO Run produces an erroneous standing oscillation component, which overpowers the eastward-propagation component around the Maritime Continent-western Pacific center. All three runs produce a too strong standing component at the eastern tropical Pacific-Central American center.

The ISO propagation is further examined in Fig. 4, where the observed and simulated ISO lifecycles in $850-\mathrm{mb}$ wind and rainfall anomalies are compared. Only the first half of the lifecycle is shown in the figure. The other half cycle is similar but with opposite signs. The color-shaded areas and black vectors denote respectively the rainfall and wind anomalies at $95 \%$ and $90 \%$ significance levels. The observed ISO (Fig. 4a) shows distinct features that initiate near the coasts of equatorial East Africa in phase 1 and propagate eastward along the equator before arriving at Borneo in phase 6 wherein the propagation slows down and later dissipates near New Guinea. While traveling across the Indian Ocean, a portion of rainfall anomalies moves northward toward the Arabian Sea, the Bay of Bengal, and the South China Sea. This northward propagation is accompanied by off-equator Rossby wave response to its northwestern quadrant, as evident in the wind anomalies. The northward ISO decays over the northern plain of India and later over the East China Sea. Two or three pentads after their arrival at the Maritime Continent, rainfall anomalies revive over the 
(a) Observation

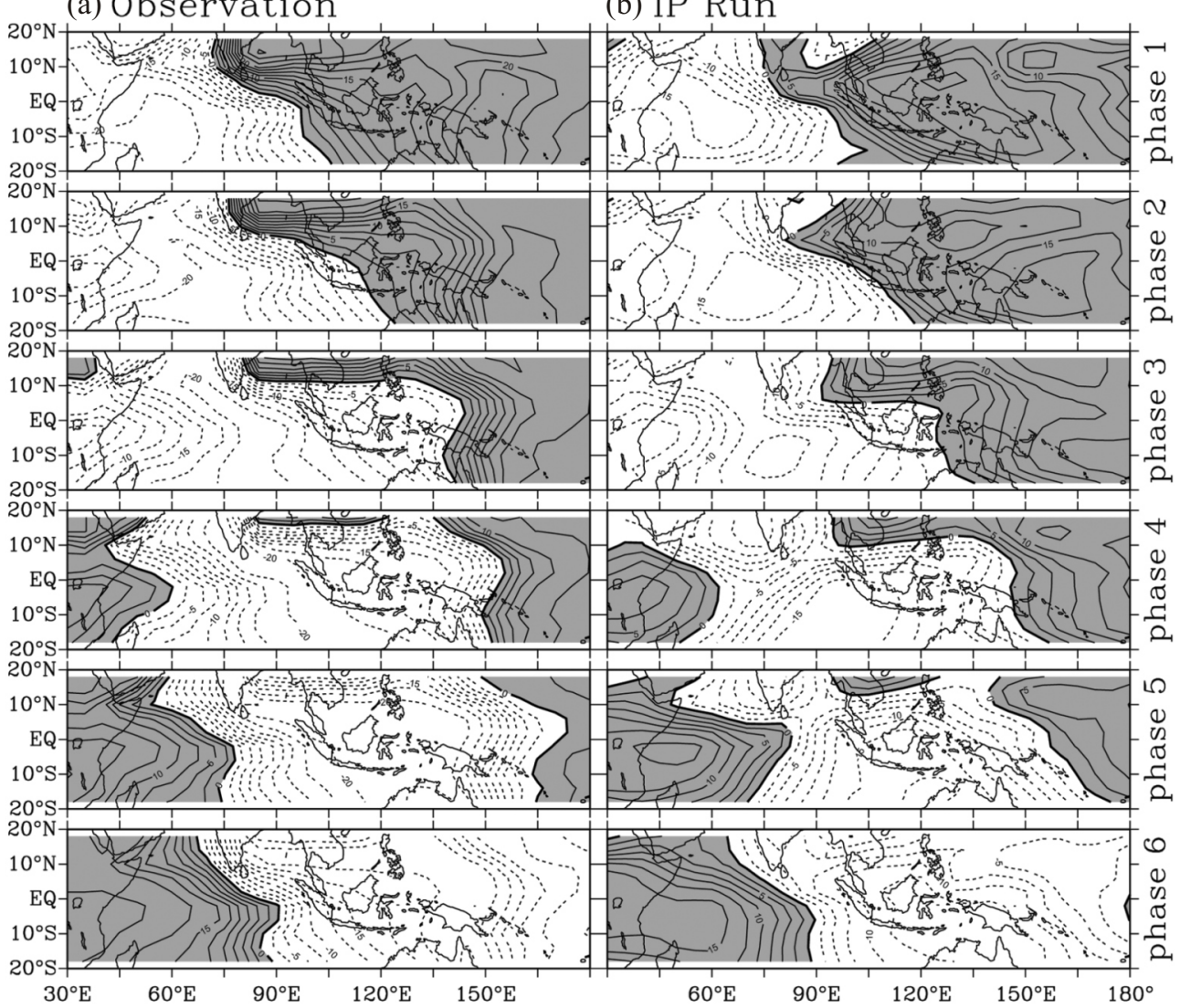

(c) PO Run

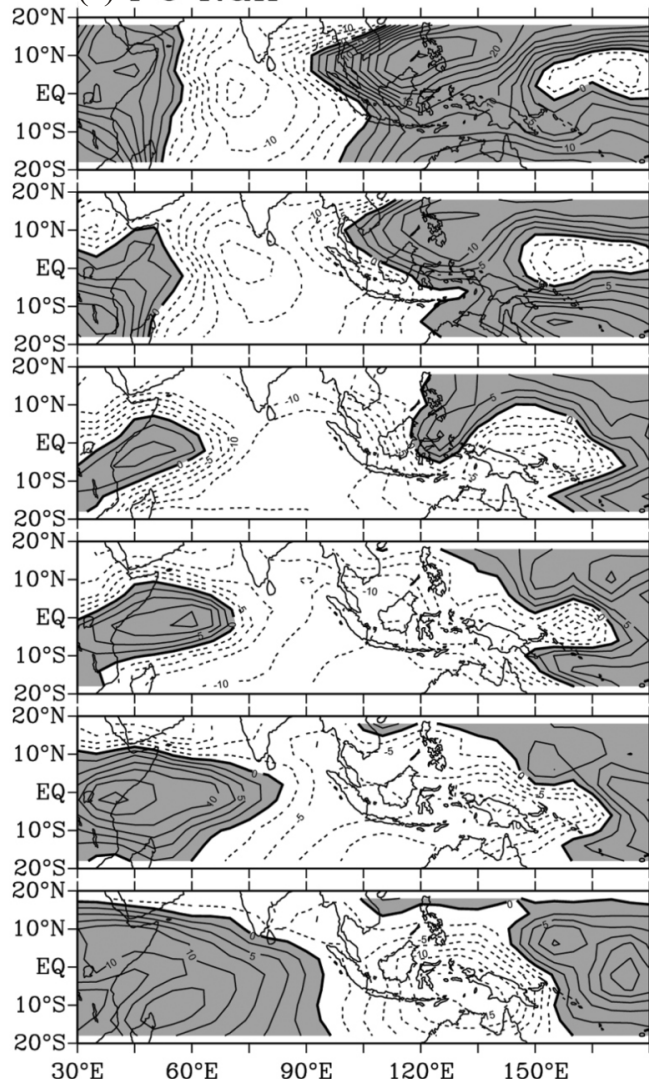

(d) IO Run

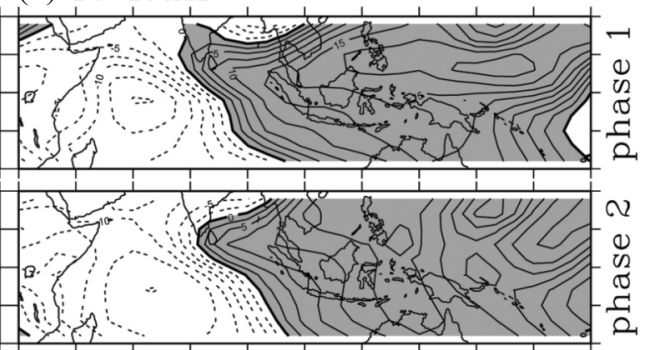

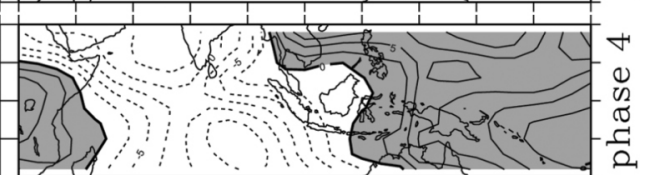
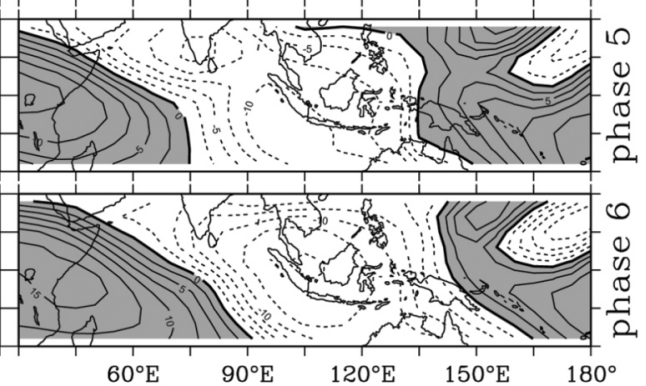

Fig. 2. Evolutions of the first EEOF mode of easterly vertical shear (EVS) anomalies in the: (a) observation, (b) Indo-Pacific (IP), (c) Pacific Ocean (PO) Run, and (d) Indian Ocean (IO) runs. Only the first half of full cycle from phase 1 ( -25 days) to phase 6 ( +0 day) is shown. 
(a) Observation

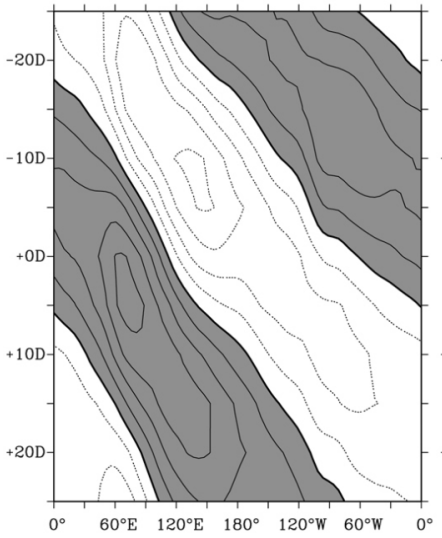

(b) IP Run

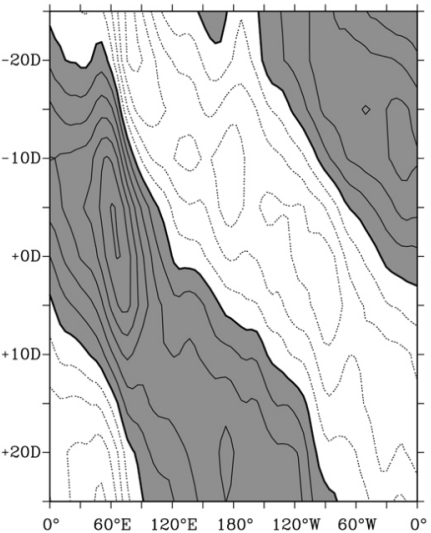

(c) PO Run

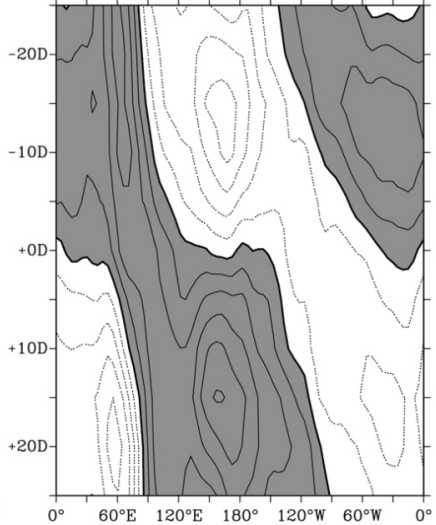

(d) IO Run

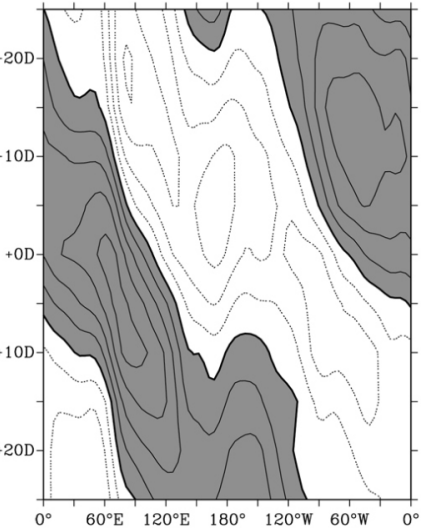

Fig. 3. Lifecycle of summertime ISO in $200 \mathrm{mb}$ velocity potential $\left(\chi_{200}^{\prime}\right)$ anomalies along the tropics berween $2^{\circ} \mathrm{S}$ and $14^{\circ} \mathrm{N}$. Panel (a) is composited from the observation, (b) from the Indo-Pacific (IP) Run, (c) from the Pacific Ocean (PO) Run, and (d) from the Indian Ocean (IO) Run. Contour intervals are $1.0 \times 10^{6} \mathrm{~m}^{2} \mathrm{sec}^{-1}$ in (a) and $1 / 3 \times 10^{6} \mathrm{~m}^{2} \mathrm{sec}^{-1}$ in (b) - (d).

(a) Observation

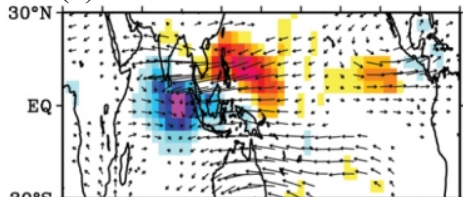

(b) IP Run

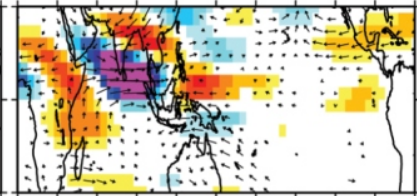

(c) PO Run

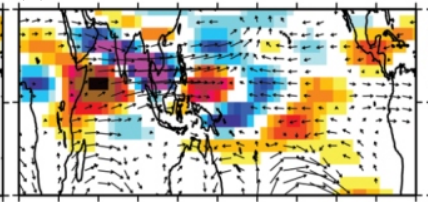

(d) IO Run

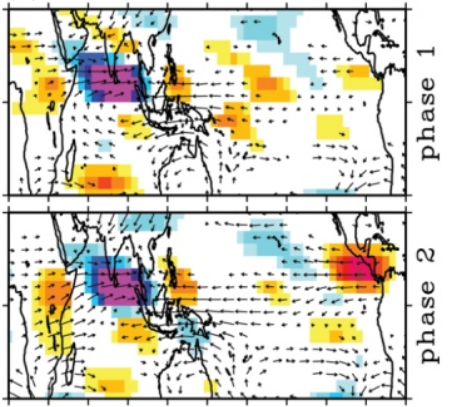

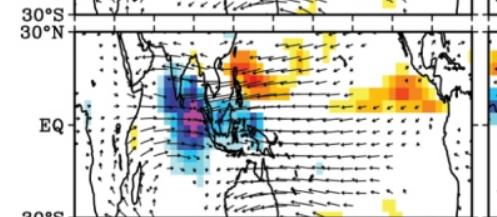
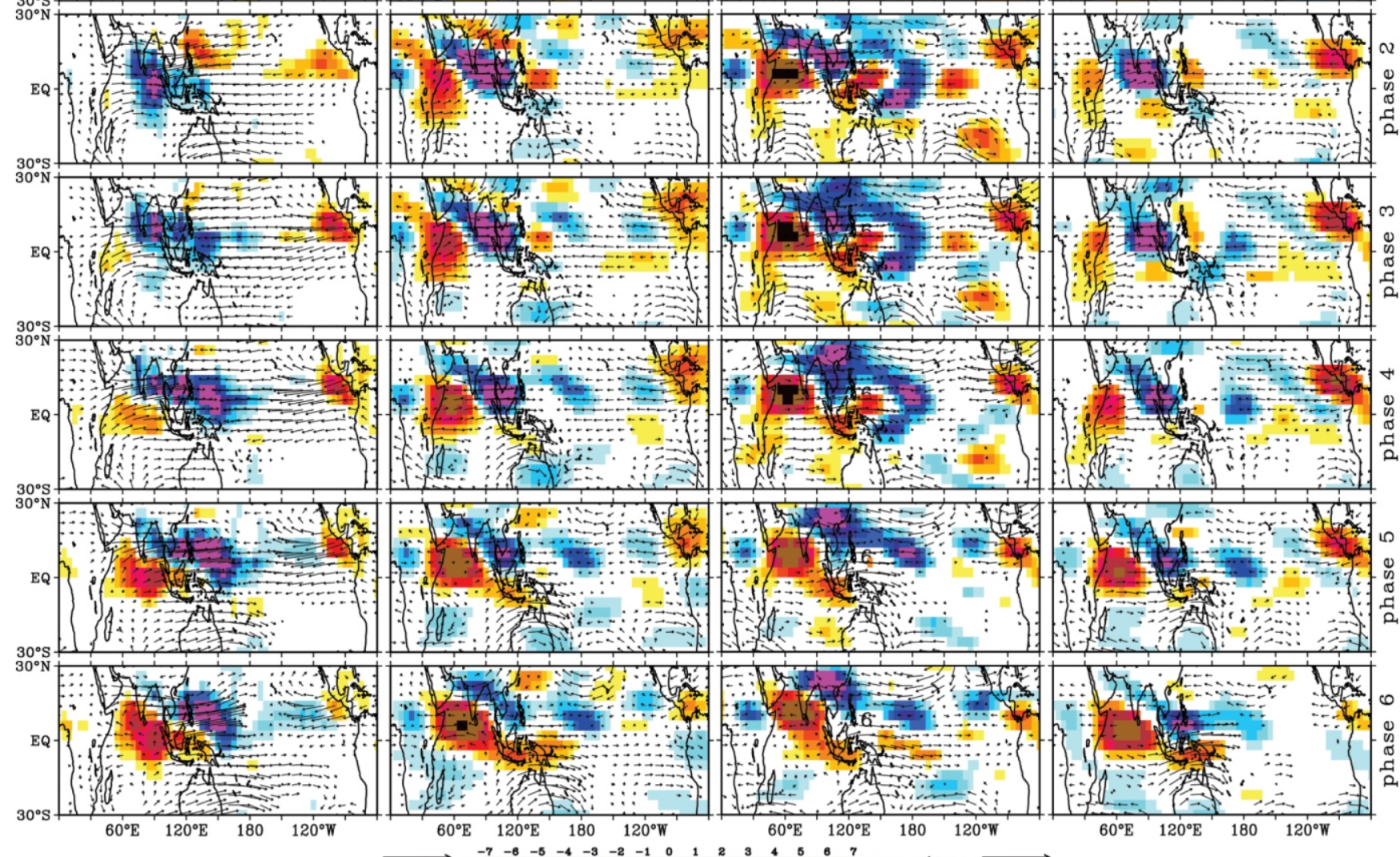

$60^{\circ} \mathrm{E} 120^{\circ} \mathrm{E} 180 \quad 120^{\circ} \mathrm{W}$
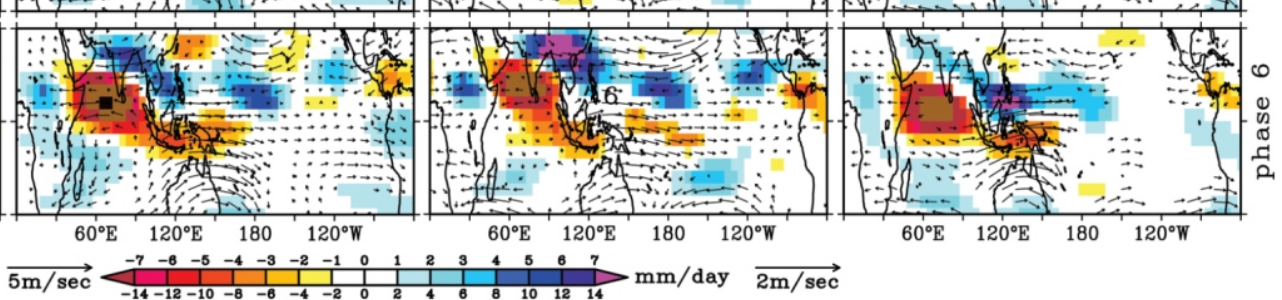

Fig. 4. The composite ISO life cycles in rainfall (color-shading) and 850-mb wind (vector) anomalies calculated from: (a) observation, (b) Indo-Pacific (IP), (c) Pacific Ocean (PO), and (d) Indian Ocean (IO) runs. Only the first half of life cycle from phase 1 ( -25 day) to phase 6 ( +0 day) and the rainfall (wind) anomalies that are significant at $95 \%(90 \%)$ confidence level are shown. The observed/simulated rainfall (wind) anomalies are scaled by the values (vector) below/above the color bar (to the left/right corner). 
western North Pacific (phase 3) and move northwestward toward Taiwan where the previous northward branches still exist. It thus results in an intraseasonally fluctuating rain band along the location of the mean monsoon trough extending from Bay of Bengal, passing through the IndoChina peninsula and South China Sea to the east of the Philippine Islands (phase 4). Interacting with SST anomalies built up from previous surface flux changes, rainfall anomalies flare up in the tropical eastern Pacific (phase 5).

Both the IP (Fig. 4b) and IO (Fig. 4d) Runs capture the zonal and northward propagating rainfall anomalies over the Indian Ocean sector. The zonal propagation produced by the IO Run in the South Asian monsoon regions is particularly realistic. The northward propagation of rainfall anomalies and the associated wind anomalies are also reasonably simulated over the Indian Peninsula. In the PO Run (Fig. 4c), standing oscillations dominate the lifecycle. Both the zonal and meridional propagation of convection anomalies are weak. In particular, the action center shifts to the western North Pacific, where the associated convection/circulation anomalies propagate westward, instead of eastward, from Philippine Sea toward Taiwan and southeastern China. In addition, they are more viable than their counterparts in the IO Run, suggesting the importance of air-sea interactions to establish the propagating characteristics of off-equator moist Rossby waves. Interestingly, the ISO over the western North Pacific and East Asia in the IP Run are weaker than in the PO Run. The Indian Ocean coupling in the IP Run seems to help reduce the amplitude of the unrealistically off-equatorial ISO. It is noted in the observation and the IP and IO Runs that anomalies in the western North Pacific have an opposite polarity from those in the eastern Indian Ocean. It is likely that the northward-propagating ISO originated from the Indian Ocean offset the westward ISO over the western North Pacific and East Asia, or vice versa. When both the Pacific and Indian Ocean couplings are included, the IP Run produce weaker (but more realistic) ISO variability in the western North Pacific than the PO Run. Results of Figs. 3 and 4 suggest that the Indian ocean coupling help promoting both the zonal and meridional propagations of the summer ISO in the Indian Ocean sector. The Pacific Ocean coupling is less important to the summer ISO propagation.

\section{ROLE OF THE OCEAN COUPLING}

To understand how ocean coupling affects the ISO propagation, we examine in Fig. 5 the evolutions of ISO-related SST and surface wind stress anomalies in the observation and three CGCM experiments. Note the different scales used in the observed and simulated anomalies. For the sake of discussion, the centers of enhanced rainfall in Fig. 4 are labeled as open triangles in the panels for the observation and the IP Run. In the observation (Fig. 5a), positive SST anomalies show a northward moving tendency which ap- pears first in the Arabian Sea and subsequently in the Bay of Bengal, South China Sea, and northern West Pacific Ocean. The SST anomalies exhibit a northwest-to-southeast tilting pattern. Enhanced rainfall anomalies are preceeded by positive SST anomalies to the north and followed by negative SST anomaloies to the south, suggesting that the coupling in the Indian Ocean help promoting the northward propagation of the summertime ISO. The IP Run (Fig. 5b) reasonably simulates the northward propagation of SST anomalies over the Arabian Sea and Bay of Bengal. The SSTA evolution in the IO Run (Fig. 5d) is similar to that in the IP Run. The largest magnitude of the simulated SST anomalies in the IP Run is about $0.3 \sim 0.5^{\circ} \mathrm{C}$, which is noticeably comparable with the observed ones. Model runs do not produce very well the observed eastward-travelling component of the SST anomalies in the low latitudes. However, such an eastward tendency does exist in both the IP and IO Runs.

We further analyze the associated surface heat fluxes to examine how the ISO-SST interactions are produced. Figure 6 shows the composited latent heat fluxes (LHF; shadings) and short-wave radiation fluxes (SWR; contours) from the observation and three CGCM runs. The sign of these flux terms is positive downward. In the observation (Fig. 6a), a well-organized pattern of positive/negative SWR anomalies with a northwest-to-southeast tilting is found to lead the positive/negative SST anomaly (SSTA) centers (marked by $+/$ - symbols in panels a and b) about $1 / 4$ cycles. Since the positive/negative SSTA also leads the regions of enhanced/suppressed rainfall anomalies about $1 / 4$ cycles (cf. Fig. 5a), the SWR anomalies, with an opposite sign, thus nearly coincide with the rainfall anomalies due to the changes of cloudiness. In response to the increased (decreased) southwesterly mean flow (see Fig. 5a), which is in turn caused by the enhanced (suppressed) rainfall to the north, the development of the negative (positive) values of LHF anomalies first appearing in the equatorial western Indian Ocean thus slightly lags that of the negative (positive) SWR anomalies. Nevertheless, with a same polarity, subsequent development of the LHF anomalies eventually catches the SWR anomalies while migrating northward towards the latitudes of the Arabian Sea, Bay of Bengal, and southern South China Sea. It is in these regions that the SST anomaly maxima appear after 1-to-2 pentads. Contrasting to the anomalous SWR pattern, which is more or less confined to the eastern hemisphere, a wavenumber 1 (and 2) LHF signal that propagates eastward along the equatorial latitudes can be recognized in both hemispheres as its main body migrates northward. It indicates that the observed planetary-scale feature of the boreal summer ISO is attributed to the underlying LHF that provides the energy source to support the perturbations growing in the free atmosphere aloft.

In the IP Run (Fig. 6b), the magnitudes of SWR anomalies are less organized and weaker than the LHF anomalies in most areas. The underestimation of the cloud-radiation-SST 
(a) Observation (b) IP Run (c) PO Run (d) IO Run

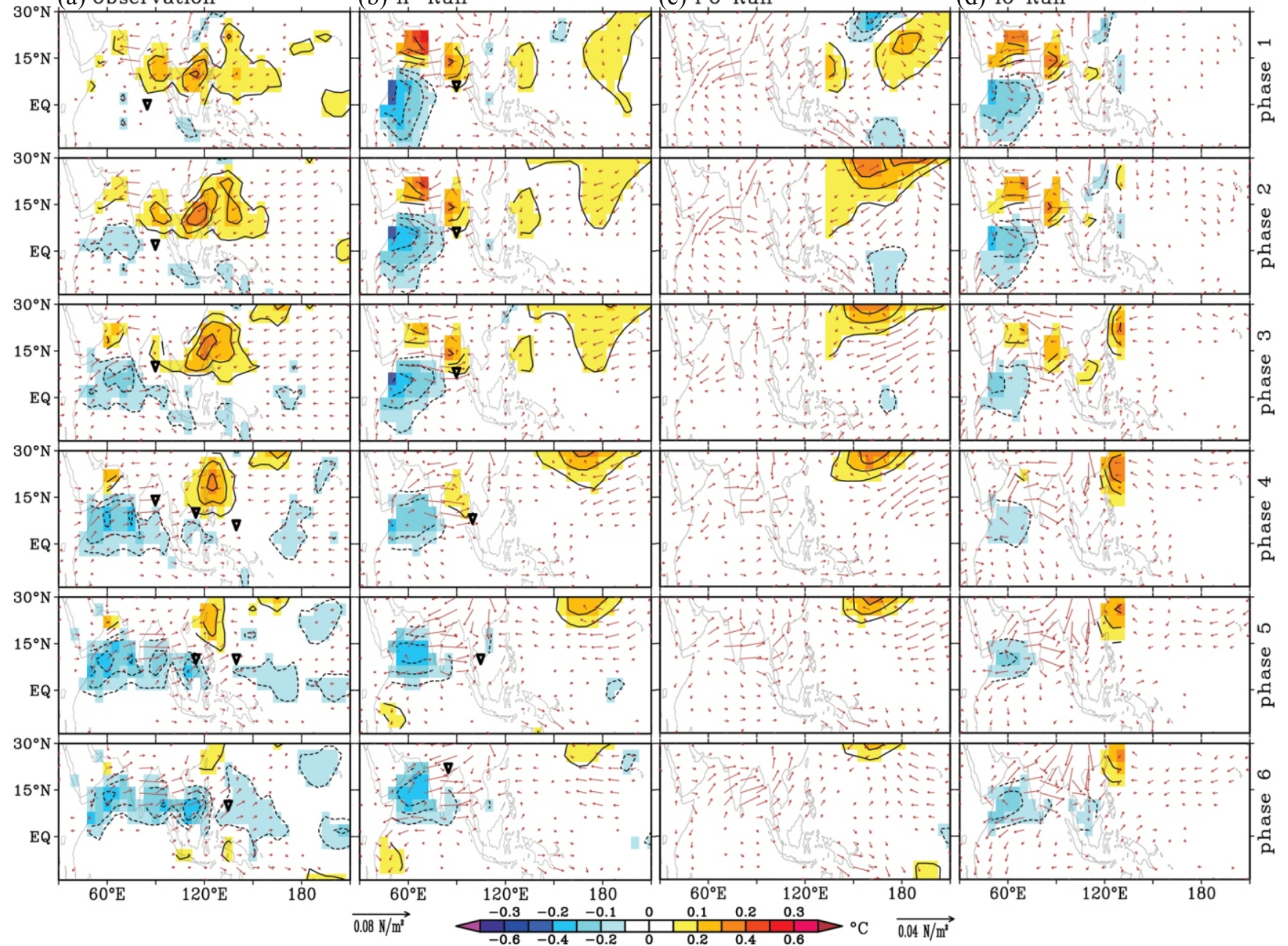

Fig. 5. The composite ISO life cycles in SST (colored shading) and surface wind stress (vector) anomalies calculated from: (a) the observation, (b) IP, (c) PO, and (d) IO runs. Centers of enhanced rainfall anomalies in Fig. 4a (b) are indicated as open triangles in Fig. 5a (b). Only the first half of lifecycle and stress anomalies significant at $90 \%$ confidence level are shown. The observed/simulated SST (stress) anomalies are scaled by the values (vector) below/above the color bar (to the left/right corner).

feedback is likely due to the way cloudiness is treated in the UCLA AGCM, which is either $100 \%$ or $0 \%$. There is no partial cloudiness in this particular model. As a result, model cloudiness is not sensitive to the weak ISO events simulated. The associated shortwave radiation flux anomalies are therefore very weak. Besides, coarse vertical resolution in this employed AGCM may not be sufficient either to fully resolve observed deep convection and accompanying subsidence in key ISO regions. It is well-known that high clouds, with a thick optical depth, play an important role in driving the tropical diabatic circulation and the occurrence of an enhanced rainfall anomaly also has a region of mid-toupper-level straitform cloudiness associated with it. The involved radiation process, which is determined by cloud properties, contributes to the observed vertical structure of diabatic heating. Various physical processes by which the cloud-radiation feedback affects the ISO deserve further model study using a finer vertical resolution.

However, relative phasings between the SWR and LHF anomalies, and their relationships with the SST and rainfall anomalies indeed show some resemblances with the observation. The similarity also includes the planetary-scale feature in the LHF anomalies captured by the IP Run. In contrast, the LHF anomalies in both the IO and PO Runs (Figs. 6c, d) largely decrease in the respected ocean basin that lacks of the air-sea coupling. Other salient features in the simulation are also noticed. In particular, the development of the northward branch of positive (negative) SWR anomalies initiated along the East African coasts is not intensive enough to offset the predominant negative (positive) LHF anomalies developing in its northeast. This can be identified in both the IP and IO Runs but not in the PO Run where the associated LHF anomalies show no propagation. As a result, the northward moving SSTA in the Arabian Sea is also largely at- 
(a) Observation

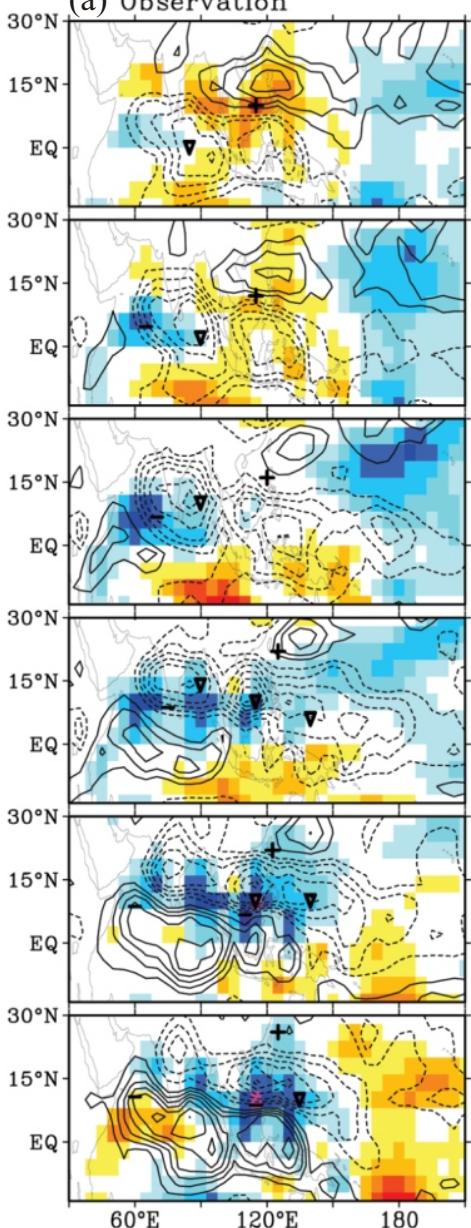

(b) IP Run
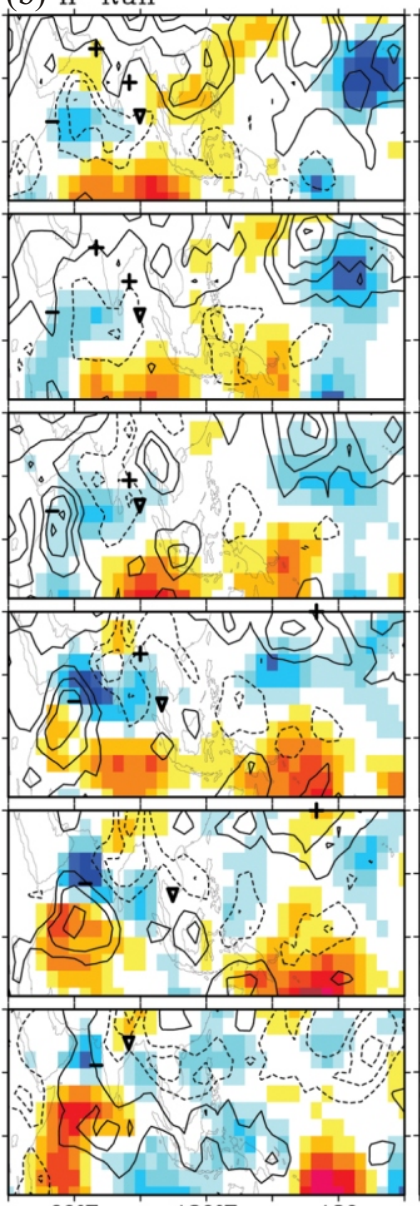

$60^{\circ} \mathrm{E}$ (c) PO Run

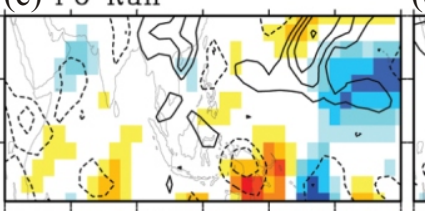

(d) IO Run

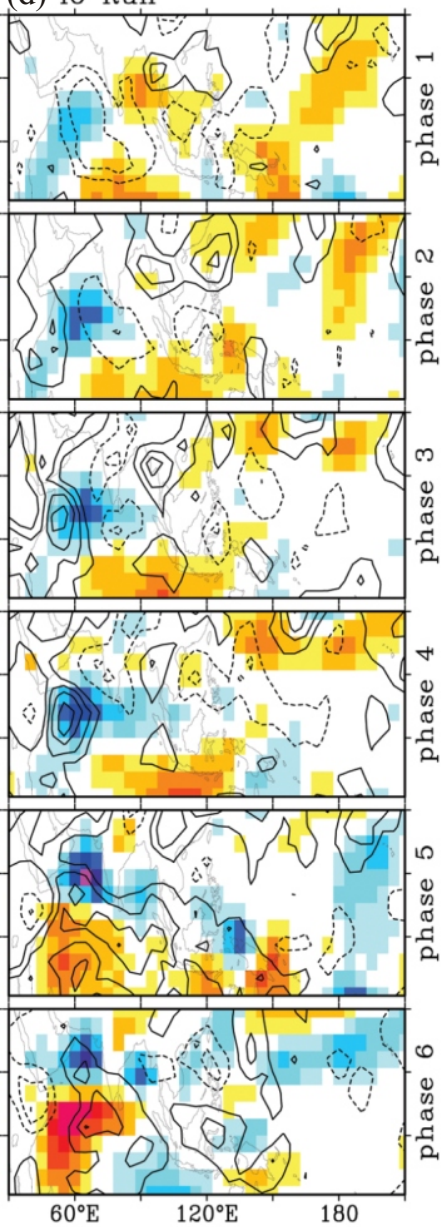

Fig. 6. The composite ISO lifecycles in latent heat ( $\mathrm{LH}$; colored shading) and short-wave radiation (SWR; contour) anomalies calculated from: (a) the observation, (b) IP, (c) PO, and (d) IO runs. Downward fluxes are positive. Centers of enhanced rainfall (in Figs. 4a, b) and positive/negative SSTA (in Figs. 5a, b) are respectively labeled as open triangles and +/- in both Figs. $6 \mathrm{a}$ and $\mathrm{b}$. The observed/simulated LH anomalies are scaled by the values below/above the color bar. Contour intervals of SWR anomalies are $5 \mathrm{~W} \mathrm{~m}^{-2}$.

tributed to the local wind-evaporation feedback rather than the cloud-radiation feedback.

According to atmospheric dynamic theories of ISO (e.g., Lau and Peng 1990; Wang and Xie 1997; Jiang et al. 2004), the mean monsoonal circulation determines the extent of the meridional propagation of summertime ISO. To examine this mechanism further, we show in Fig. 7 the distributions of mean EVS in the observation and three model experiments. Here the EVS serves as an index to measure the strength of the summer monsoon, similar to the monsoon circulation index defined by Webster and Yang (1992). The larger the negative EVS values, the stronger the summer monsoon. In the observation (Fig. 7a), negative EVS values extending from the Arabian Sea, the Bay of Bengal, to the South China Sea, coincide reasonably with the regions where the northward ISO propagations are observed (cf. Fig. 4a). The northernmost extent of the ISO propagation also appears to be limited by the boundary of the zero contours (near $25^{\circ} \mathrm{N}$ ). Among all three runs, the PO Run (Fig. 7c) produces the most realistic EVS pattern with extreme values (dark shaded areas) covering a wider meridional extent than that in both the IP (Fig. 7b) and IO (Fig. 7d) Runs. This indicates that the PO Run produces a more realistic Asian summer monsoon circulation, probably because its Indian Ocean SSTs are prescribed with the observation. However, the PO Run does not produce a significant ISO propagating northward. Furthermore, in the IP and IO Runs, the northward ISO propagations go beyond their corresponding negative EVS domains. These basin-coupling results suggest that the northward ISO propagation cannot be explained solely as a result of atmospheric internal dynamics. Instead, the air-sea coupling in the Indian Ocean is also important to the summertime ISO dynamics.

We further contrast the ISO simulations produced by the 
(a) Observation

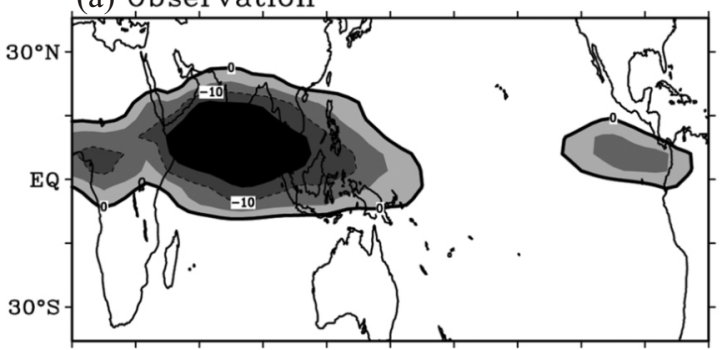

(c) PO Run

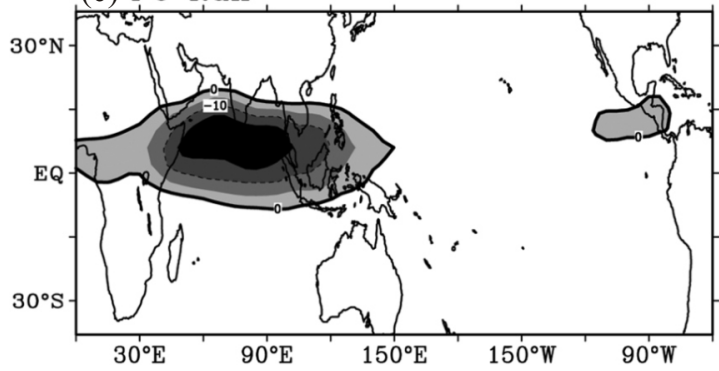

(b) IP Run

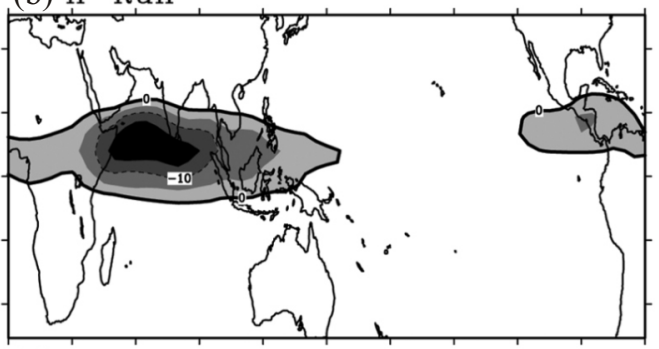

(d) IO Run

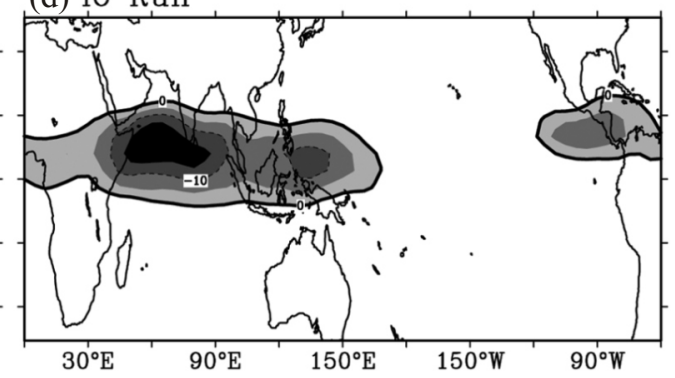

Fig. 7. The climatic mean EVS (easterly verical shear) calculated from: (a) the observation, (b) IP, (c) PO, and (d) IO runs in MJJASO. Only negative values of EVS are shaded and contoured with $5 \mathrm{~m} \mathrm{sec}^{-1}$ intervals.

basin-coupling runs with those from their corresponding forced AGCM runs. Monthly SST climatologies produced by the CGCM experiments are used as boundary conditions in the respected coupled ocean basins to drive the same AGCM in an uncoupled configuration. Outside the forced ocean domains, SSTs are still prescribed from the observed monthly-mean climatology. All AGCM runs are integrated for about 13 years, and the last 10 years of the simulations are analyzed. The same EEOF analysis and composite procedure are applied to the AGCM runs to construct the lifecycle of the simulated ISO. Figure 8 shows the evolutions of the summertime $\chi^{\prime}{ }_{200}$ along the low latitudes (averaged between $2^{\circ} \mathrm{S}$ and $14^{\circ} \mathrm{N}$ ). The standing $\chi^{\prime}{ }_{200}$ oscillation produced by the forced PO Run (Fig. $8 \mathrm{~b}$ ) is very similar to that of the coupled PO Run (Fig. 3c), confirming again that the model SST biases in the Pacific Ocean cause the standing ISO feature and that the coupling in the Pacific Ocean does not promote the ISO propagation. For the forced IO Run (Fig. 8c), the $\chi_{200}^{\prime}$ shows a stronger standing but weaker propagating feature in the Indian Ocean than the coupled IO Run (Fig. 3d). The difference between them indicates that the standing feature is caused by the CGCM biases in the Indian Ocean SSTs and also that it requires the Indian Ocean coupling to enhance the zonal propagation of the summertime ISO. It is noted in Fig. 8c that the Indian Ocean SST biases also enhance the standing $\chi_{200}^{\prime}$ oscillation centered at the dateline. The differences in $\chi_{200}^{\prime}$ between the forced (Fig. 8a) and the coupled (Fig. 3b) IP Runs are similar to those between the forced (Fig. 8c) and the coupled IO (Fig. 3d) Runs. It should be noted over the Indian Ocean sector $\left(60-120^{\circ} \mathrm{E}\right)$ that the eastward propagating feature can still be identified in the forced IP and IO runs (Figs. 8a, c), although less obvious than in their corresponding CGCM runs. It then suggests that the atmospheric internal dynamics also contribute to the zonal propagation of summertime ISO. This possible active role of the atmosphere itself in the ISO related air-sea interaction is indicated by comparing the SST and heat flux with the surface wind stress anomalies (see Figs. 5, 6). The westerly anomalies to the west of anomalous convection, for example, will retrieve LHF from ocean (thus cool the SST) and deliver moisture to the convection center, which manifests the important air-sea coupling process. However, it is the atmosphere that decides the location to extract heat from the ocean whereas the ocean reacts passively. This spatiotemporal relationship can only be sustained in the CGCM. Lacking of this wind-evaporation effect in the AGCM, the zonal propagation tendency due to the atmospheric internal dynamics is likely slowed down or locked by the local positive SST, resulting in the simulated oscillation being more stationary.

To highlight the relative roles between the ocean coupling and atmospheric internal dynamics upon the northward propagating ISO in boreal summer, we show in Fig. 9 the time-latitude plots of the $U_{850}^{\prime}$ (contours) and rainfall (color-shaded) composites in the observation and various model experiments around the longitudes of the Bay of Bengal (averaged between 85 and $95^{\circ} \mathrm{E}$ ). Some salient features are as follows. Firstly, lack of the coupling not only results in the reduction of anomalous magnitude but also the weakening of the propagating feature in the ISO-related convection (panel b vs. $d$ and panel c vs. e), consistent with the findings in some recent studies (e.g., Fu and Wang 
(a) Forced IP Run

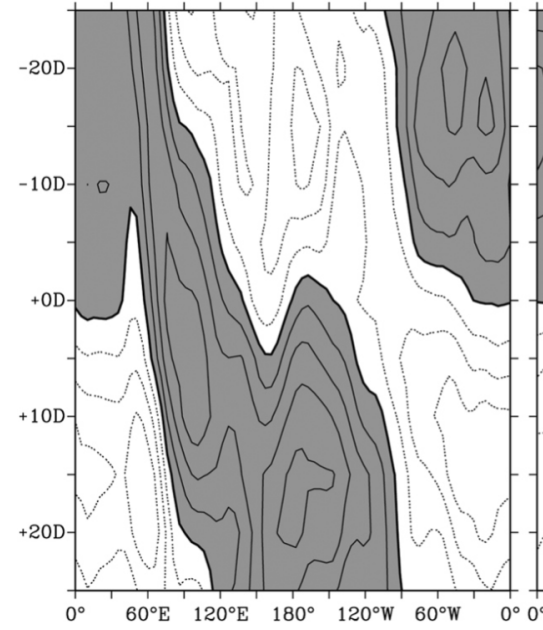

(b) Forced PO Run

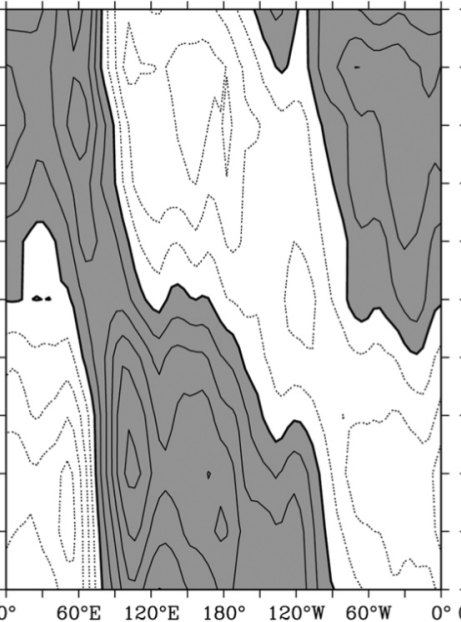

(c) Forced IO Run

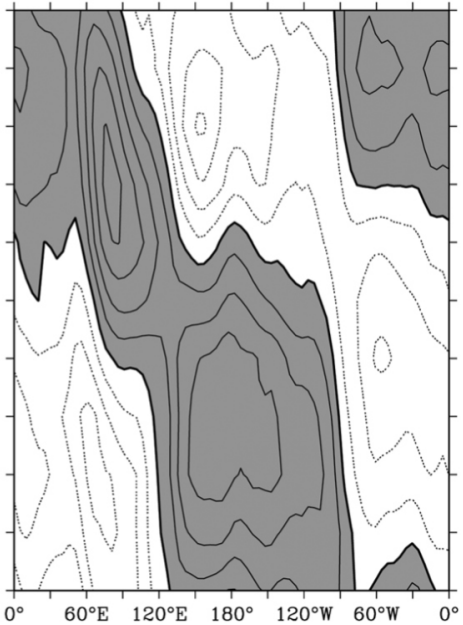

Fig. 8. The Hovmöller diagrams of the compositing summertime $\chi_{200}^{\prime}$ from the: (a) forced IP, (b) forced PO, and (c) forced IO AGCM experiments averaged between $2^{\circ} \mathrm{S}$ and $14^{\circ} \mathrm{N}$. Contour intervals are $1 / 3 \times 10^{6} \mathrm{~m}^{2} \mathrm{sec}^{-1}$.

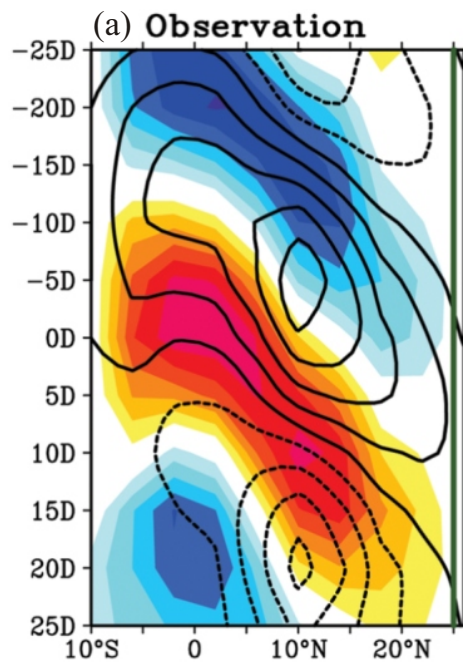

(b) IP Run

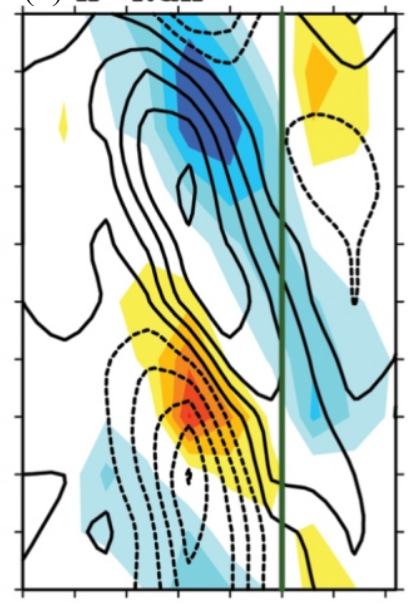

(d) forced IP Run

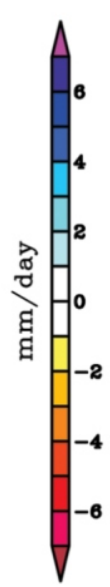

(c) IO Run

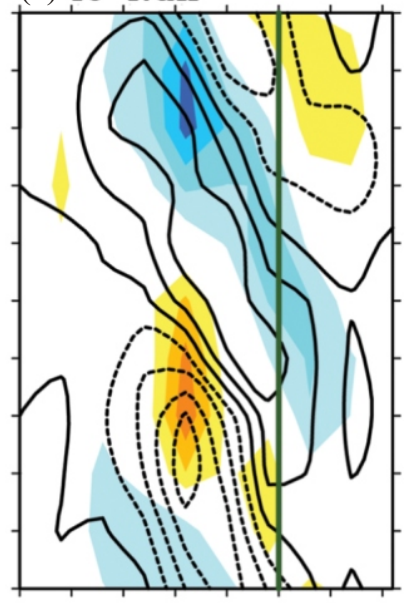

(e) forced IO Run

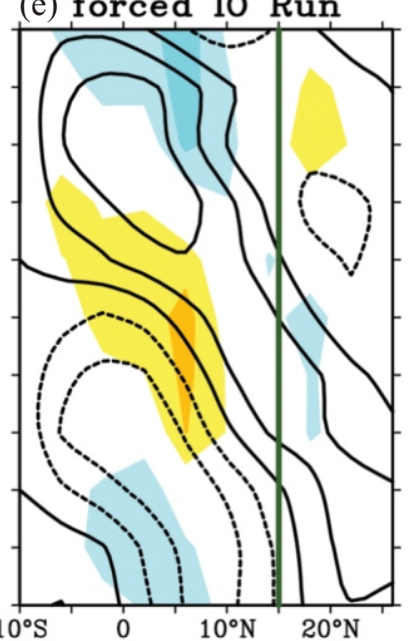

Fig. 9. The time-latitude diagrams of the summertime $U_{850}^{\prime}$ (contour lines; solid: westerly) and rainfall (color shading) composites in: (a) the observation, (b) IP, (c) IO, (d) forced IP, and (e) forced IO runs. The anomalies are longitudinally averaged between 85 and $95^{\circ} \mathrm{E}$ roughly around the Bay of Bengal. Contour interval of $\mathrm{U}_{850}^{\prime}$ is $1.0 \mathrm{~m} \mathrm{sec}^{-1}$ in panel (a), and $0.5 \mathrm{~m} \mathrm{sec}^{-1}$ elsewhere. The vertical green lines mark the averaged locations of zero contours in the seasonal-mean EVS. 
2004). Secondly, the evolution of $U_{850}^{\prime}$ somewhat still owes a northward propagating signal even if the Indian Ocean coupling is absent (panel e), suggesting the increased role of atmospheric internal dynamics to aid the ISO propagation when an asymmetric monsoonal circulation appears in boreal summer (Wang and Xie 1997). Finally, when the air-sea coupling is excluded in the forced IP Run (panel d), the northernmost latitude (around $15^{\circ} \mathrm{N}$; vertical green line) that the dwindling zonal winds' propagation can reach coincides with the northern boundary of seasonal-mean negative EVS (cf. Fig. 7b). However, it is not the case in the corresponding coupled run (panel b) that allows the simulated $\mathrm{U}^{\prime}{ }_{850}$ to cross the northern boundary of seasonal-mean negative EVS and thus leads to a latitudinal extent closer to the observation. Although it could be model dependent, it leads us to conclude that the Indian Ocean coupling plays an important rather than a secondary role in the northward propagation of ISO in boreal summer.

\section{SUMMARY AND CONCLUSIONS}

In this study, we demonstrated with three basin-coupling CGCM experiments that the Indian Ocean coupling is crucial to the strength and extent of the meridional propagation of summertime ISO. In boreal summer, when the warm SSTs retract westward and shift into the Northern Hemisphere, the northward propagating component strengthens while its eastward propagating component weakens. The propagation mainly occurs in the northern Indian Ocean and the western North Pacific, allowing the Indian Ocean coupling to become important. The Pacific Ocean coupling is less important to the summertime ISO. The IO Run produces the most realistic simulation of the northward ISO propagation, while the PO Run fails to simulate the northward propagation. Our composite analyses revealed that the ocean couplings promote the ISO propagations by configuring a proper temporal and spatial phase relationship between the surface fluxes, winds, convection, and underlying SST fluctuations. In this particular CGCM, however, the ISO-SST interaction is generated mainly by the wind-evaporation feedback through which the anomalous LHF changes the SST and thereby the anomalous convection. In the observations, an interaction is also produced via short wave radiation flux through the convection-cloud feedback. From the forced AGCM experiments, we found that the meridional ISO propagation weakens once the ocean couplings are turned off.

The relative roles of the air-sea coupling in the Indian Ocean and the off-equator monsoon mean flow in shaping the summertime ISO are further examined by comparing the coupled runs with their forced AGCM counterparts. Results indicate that: 1) the northward propagating feature in the ISO-related convection is enhanced when an interactive Indian Ocean is included; 2) the atmospheric internal dy- namics aid the propagating feature of the ISO mainly through the associated low-level zonal winds, though with reduced magnitude when the coupling is excluded; and 3) Indian Ocean coupling helps the simulated ISO to cross the northern boundary of mean negative EVS, resulting in a more realistic simulation. This study therefore concludes that the Indian Ocean coupling plays an important rather than secondary role in the northward propagation of the ISO in boreal summer.

Acknowledgements The authors thank two reviewers for their valuable comments on the manuscript. The suggestions from John Farrara are especially appreciated. Special thanks are extended to Wen-Haung Huang for his help in figure preparation. SPW was supported by the National Science Council of Taiwan under Grant NSC 95-2111-M003-002. JYY was supported by the National Science Foundation of USA under Grant NSF ATM-0321380. Model simulations were performed at the University of California Irvine's Earth System Modeling Facility and the UC San Diego Supercomputer Center.

\section{REFERENCES}

Bhat, G. S., S. Gadgil, P. V. Hareesh Kumar, S. R. Kalsi, P. Madhusoodanan, V. S. N. Murty, C. V. K. Prasada Rao, V. Ramesh Babu, L. V. G. Rao, R. R. Rao, M. Ravichandran, K. G. Reddy, P. Sanjeeva Rao, D. Sengupta, D. R. Sikka, J. Swain, and P. N. Vinayachandran, 2001: BOBMEX: The Bay of Bengal Monsoon Experiment. Bull. Amer. Meteor. Soc., 82, 2217-2243, doi: 10.1175/1520-0477(2001)082 $<2217$ :BTBOBM $>2.3 . \mathrm{CO} ; 2$. [Link]

Bryan, K., 1969: A numerical method for the study of the circulation of the world ocean. J. Comput. Phys., 4, 347-376, doi: 10.1016/0021-9991(69)90004-7. [Link]

Chen, T. C. and J. M. Chen, 1995: An observational study of the South China Sea monsoon during the 1979 Summer: Onset and life cycle. Mon. Wea. Rev., 123, 2295-2318, doi: 10.1175/1520-0493(1995)123<2295:AOSOTS >2.0.CO;2. [Link]

Chen, T. C., R. Y. Tzeng, and M. C. Yen, 1988: Development and life cycle of the Indian monsoon: Effect of the 30-50 day oscillation. Mon. Wea. Rev., 116, 2183-2199, doi: 10.1175/1520-0493(1988)116<2183:DALCOT>2.0.CO;2. [Link]

Cox, M. D., 1984: A primitive equation three-dimensional model of the ocean. GFDL Ocean Group Tech. Rep. No.1, $75 \mathrm{pp}$.

$\mathrm{Fu}, \mathrm{X}$. and B. Wang, 2004: Differences of boreal-summer intraseasonal oscillations simulated in an atmosphere-ocean coupled model and an atmosphere-only model. J. Clim., 17, 1263-1271, doi: 10.1175/1520-0442(2004)017<1263: DOBSIO $>2.0 . \mathrm{CO}$;2. [Link]

Goswami, B. N. and J. Shulka, 1984: Quasi-periodic oscillations in a symmetric general circulation model. J. Atmos. 
Sci., 41, 20-37, doi: 10.1175/1520-0469(1984)041<0020: QPOIAS > 2.0.CO;2. [Link]

Hall, J. D., A. J. Matthews, and D. J. Karoly, 2001: The modulation of tropical cyclone activity in the Australian region by the Madden-Julian Oscillation. Mon. Wea. Rev., 129, 2970-2982, doi: 10.1175/1520-0493(2001)129<2970: TMOTCA > 2.0.CO;2. [Link]

Hendon, H. H., C. Zhang, and J. D. Glick, 1999: Interannual variation of the Maddem-Julian oscillation during austral summer. J. Climate, 12, 2538-2550, doi: 10.1175/15200442(1999)012<2538:IVOTMJ>2.0.CO;2. [Link]

Hsu, H. H. and C. H. Weng, 2001: Northwestward propagation of the intraseasonal oscillation in the western north Pacific during the boreal summer: Structure and mechanism. $J$. Climate, 14, 3834-3850, doi: 10.1175/1520-0442(2001) 014<3834:NPOTIO $>2.0 . \mathrm{CO} ; 2$. [Link]

Hsu, H. H., C. H. Weng, and C. H. Wu, 2004: Contrasting characteristics between the northward and eastward propagation of the intraseasonal oscillation during the boreal summer. J. Climate, 17, 727-743, doi: 10.1175/1520-0442 (2004)017<0727:CCBTNA>2.0.CO;2. [Link]

Hung, C. W. and M. Yanai, 2004: Factors contributing to the onset of the Australian summer monsoon. Q. J. R. Meteorol. Soc., 130, 739-758, doi: 10.1256/qj.02.191. [Link]

Jiang, X., T. Li, and B. Wang, 2004: Structures and mechanisms of the northward propagating boreal summer intraseasonal oscillation. J. Climate, 17, 1022-1039, doi: 10.1175/ 1520-0442(2004)017<1022:SAMOTN>2.0.CO;2. [Link]

Jones, C., L. M. V. Carvalho, R. W. Higgins, D. E. Waliser, and J. K. E. Schemm, 2004: Climatology of tropical intraseasonal convective anomalies 1979-2004. J. Climate, 17, 523-539, doi: 10.1175/1520-0442(2004)017<0523: COTICA $>2.0 . \mathrm{CO} ; 2$. [Link]

Kemball-Cook, S. R. and B. Wang, 2001: Equatorial waves and air-sea interaction in the boreal summer intraseasonal oscillation. J. Climate, 14, 2923-2942, doi: 10.1175/15200442(2001)014<2923:EWAASI>2.0.CO;2. [Link]

Kim, J. H., C. H. Ho, H. S. Kim, C. H. Sui, and S. K. Park, 2008: Systematic variation of summertime tropical cyclone activity in the western North Pacific in relation to the Madden-Julian Oscillation. J. Climate, 21, 1171-1191, doi: 10.1175/2007JCLI1493.1. [Link]

Lau, K. M. and P. H. Chan, 1986: Aspects of the 40-50 day oscillation during the northern summer as inferred from outgoing longwave radiation. Mon. Wea. Rev., 114, 13541367, doi: 10.1175/1520-0493(1986)114<1354:AOTDOD> 2.0.CO;2. [Link]

Lau, K.-M. and L. Peng, 1990: Origin of low frequency (intraseasonal) oscillations in the tropical atmosphere. Part III: Monsoon dynamics. J. Atmos. Sci., 47, 1443-1462, doi: 10.1175/1520-0469(1990)047<1443:OOLFOI>2.0.CO;2. [Link]

Li, T. and B. Wang, 2005: A review on the western North Pacific monsoon: Synoptic-to-interannual variabilities. Terr. Atmos. Ocean. Sci., 16, 285-314.
Liebmann, B., H. Hendon, and J. Glick, 1994: The relationship between tropical cyclones of the western Pacific and Indian oceans and the Madden-Julian Oscillation. J. Meteorol. Soc. Jpn., 72, 401-411.

Madden, R. A. and P. R. Julian, 1994: Observations of the 40-50 day tropical oscillation: A review. Mon. Wea. Rev., 112, 814-837, doi: 10.1175/1520-0493(1994)122<0814: OOTDTO $>2.0 . \mathrm{CO} ; 2$. [Link]

Maloney, E. D. and D. L. Hartmann, 2000a: Modulation of hurricane activity in the Gulf of Mexico by the MaddenJulian oscillation. Science, 287, 2002-2004, doi: 10.1126/ science.287.5460.2002. [Link]

Maloney, E. D. and D. L. Hartmann, 2000b: Modulation of eastern North Pacific hurricanes by the Madden-Julian Oscillation. J. Climate, 13, 1451-1460, doi: 10.1175/1520-0442 (2000)013<1451:MOENPH>2.0.CO;2. [Link]

Maloney, E. D. and J. T. Kiehl, 2002: MJO related SST variations over the tropical eastern Pacific during Northern Hemisphere summer. J. Climate, 15, 675-689, doi: 10.1175/ 1520-0442(2002)015<0675:MRSVOT>2.0.CO;2. [Link]

McPhaden, M. J., 1999: Genesis and evolution of the 1997-98 El Niño. Science, 283, 950-954, doi: 10.1126/science.283. 5404.950. [Link]

Mechoso, C. R., A. W. Robertson, N. Barth, M. K. Davey, P. Delecluse, P. R. Gent, S. Ineson, B. Kirtman, M. Latif, H. Le Treut, T. Nagai, J. D. Neelin, S. G. H. Philander, J. Polcher, P. S. Schopf, T. Stockdale, M. J. Suarez, L. Terray, O. Thual, and J. J. Tribbia, 1995: The seasonal cycle over the tropical Pacific in Coupled Ocean-Atmosphere General Circulation Models. Mon. Wea. Rev., 123, 2825-2838, doi: 10.1175/1520-0493(1995)123<2825:TSCOTT $>2.0$. $\mathrm{CO} ; 2$. [Link]

Mechoso, C. R., J. Y. Yu, and A. Arakawa, 2000: A coupled GCM pilgrimage: From climate catastrophe to ENSO simulations. In: Randall, D. A. (Ed.), General Circulation Model Development: Past, Present, and Future. Academic Press, London, 539-575.

Murakami, T., L. X. Chen, and A. Xie, 1986: Relationship among seasonal cycle, low-frequency oscillations, and transient disturbances as revealed from outgoing longwave radiation data. Mon. Wea. Rev., 114, 1456-1465, doi: 10.1175/1520-0493(1986)114<1456:RASCLF>2.0.CO;2. [Link]

Penland, C., 1996: A stochastic model of IndoPacific sea surface temperature anomalies. Physica, D98, 534-558, doi: 10.1016/0167-2789(96)00124-8. [Link]

Reynolds, R. W., N. A. Rayner, T. M. Smith, D. C. Stokes, and W. Wang, 2002: An improved in situ and satellite SST analysis for climate. J. Climate, 15, 1609-1625, doi: 10.1175/1520-0442(2002)015<1609:AIISAS>2.0.CO;2. [Link]

Rui, H. and B. Wang, 1990: Development characteristics and dynamic structure of tropical intraseasonal convection anomalies. J. Atmos. Sci., 47, 357-379, doi: 10.1175/15200469(1990)047<0357:DCADSO>2.0.CO;2. [Link] 
Uppala, S. M., P. W. KÅllberg, A. J. Simmons, U. Andrae, V. Da Costa Bechtold, M. Fiorino, J. K. Gibson, J. Haseler, A. Hernandez, G. A. Kelly, X. Li, K. Onogi, S. Saarinen, N. Sokka, R. P. Allan, E. Andersson, K. Arpe, M. A. Balmaseda, A. C. M. Beljaars, L. Van De Berg, J. Bidlot, N. Bormann, S. Caires, F. Chevallier, A. Dethof, M. Dragosavac, M. Fisher, M. Fuentes, S. Hagemann, E. Hólm, B. J. Hoskins, L. Isaksen, P. A. E. M. Janssen, R. Jenne, A. P. Mcnally, J.-F. Mahfouf, J.-J. Morcrette, N. A. Rayner, R. W. Saunders, P. Simon, A. Sterl, K. E. Trenberth, A. Untch, D. Vasiljevic, P. Viterbo, and J. Woollen, 2005: The ERA-40 re-analysis. Q. J. R. Meteorol. Soc., 131, 2961-3012, doi: 10.1256/ qj.04.176. [Link]

Wang, B., 2005: Theory. In: Lau, K.-M. and D. E. Waliser (Eds.), Tropical Intraseasonal Oscillation in the Atmosphere and Ocean. Praxis Publishing Ltd., Chichester, UK, 307-360, doi: 10.1007/3-540-27250-X_10. [Link]

Wang, B. and H. Rui, 1990: Synoptic climatology of transient tropical intraseasonal convection anomalies: 1975-1985. Meteorol. Atmos. Phys., 44, 43-61, doi: 10.1007/BF 01026810. [Link]

Wang, B. and X. Xie, 1997: A model for the boreal summer intraseasonal oscillation. J. Atmos. Sci., 54, 72-86, doi: 10.1175/1520-0469(1997)054<0072:AMFTBS>2.0.CO;2. [Link]

Wang, B. and Z. Fan, 1999: Choice of South Asian summer monsoon indices. Bull. Amer. Meteor. Soc., 80, 629-638, doi: 10.1175/1520-0477(1999)080<0629:COSASM>2.0. $\mathrm{CO} ; 2$. [Link]

Watterson, I. G. and J. Syktus, 2007: The influence of air-sea interaction on the Madden-Julian Oscillation: The role of seasonal mean state. Climate Dyn., 28, 703-722, doi: 10.1007/s00382-006-0206-9. [Link]

Weare, B. C. and J. S. Nasstrom, 1982: Examples of extended empirical orthogonal functions. Mon. Wea. Rev., 110, 481485, doi: 10.1175/1520-0493(1982)110<0481:EOEEOF> 2.0.CO;2. [Link]

Webster, P. J., 1983: Mechanisms of monsoon low-frequency variability: Surface hydrological effects. J. Atmos. Sci., 40, 2110-2124, doi: 10.1175/1520-0469(1983)040<2110: MOMLFV $>2.0 . \mathrm{CO} ; 2$. [Link]

Webster, P. J. and S. Yang, 1992: Monsoon and ENSO: Selec- tively interactive systems. Q. J. R. Meteorol. Soc., 118, 877-926, doi: 10.1002/qj.49711850705. [Link]

Webster, P. J., E. F. Bradley, C. W. Fairall, J. S. Godfrey, P. Hacker, R. A. Houze Jr., R. Lukas, Y. Serra, J. M. Hummon, T. D. M. Lawrence, C. A. Russell, M. N. Ryan, K. Sahami, and P. Zuidema, 2002: The JASMINE pilot study. Bull. Amer. Meteor. Soc., 83, 1603-1630, doi: 10.1175/BAMS83-11-1603(2002)083<1603:TJPS > 2.3.CO;2. [Link]

Weng, S. P. and J. Y. Yu, 2010: Impacts of Pacific and Indian Ocean coupling on wintertime tropical intraseasonal oscillation: A basin-coupling CGCM study. Int. J. Climatol., 30, 359-371, doi: 10.1002/joc.1902. [Link]

Wheeler, M. C. and H. H. Hendon, 2004: An all-season realtime multivariate MJO index: Development of an index for monitoring and prediction. Mon. Wea. Rev., 132, 19171932, doi: 10.1175/1520-0493(2004)132<1917: AARMMI> 2.0.CO;2. [Link]

Woolnough, S. J., J. M. Slingo, and B. J. Hoskins, 2000: The relationship between convection and sea surface temperature on intraseasonal timescales. J. Climate, 13, 2086-2104, doi: 10.1175/1520-0442(2000)013<2086:TRBCAS >2.0. CO;2. [Link]

Xie, P. and P. A. Arkin, 1997: Global precipitation: A 17-year monthly analysis based on gauge observations, satellite estimates, and numerical model outputs. Bull. Amer. Meteor. Soc., 78, 2539-2558, doi: 10.1175/1520-0477(1997)078 $<2539$ :GPAYMA>2.0.CO;2. [Link]

Yasunari, T., 1980: A quasi-stationary appearance of 30- to 40-day period in the cloudiness fluctuations during the summer monsoon over India. J. Meteorol. Soc. Jpn., 58, 225-229.

Yu, J. Y. and C. R. Mechoso, 2001: A coupled atmosphereocean GCM study of the ENSO cycle. J. Climate, 14, 2329-2350, doi: 10.1175/1520-0442(2001)014<2329: ACAOGS $>2.0 . C O ; 2$. [Link]

Yu, J. Y, C. R. Mechoso, J. C. McWilliams, and A. Arakawa, 2002: Impacts of the Indian Ocean on the ENSO cycle. Geophys. Res. Lett., 29, doi: 10.1029/2001GL014098. [Link]

Zhang, C., 2005: Madden-Julian Oscillation. Rev. Geophys., 43, RG2003, doi: 10.1029/2004RG000158. [Link] 